\title{
Detection of Distinct Changes in Gene-expression Profiles in Specimens of Tumors and Transition Zones of Tenascin- positive/-negative Head and Neck Squamous Cell Carcinoma
}

\author{
VERONIKA ZIVICOVA ${ }^{1,2}$, PETER GAL $^{3,4}$, ALZBETA MIFKOVA $^{1,2}$, STEPAN NOVAK $^{1,2}$, HERBERT KALTNER $^{5}$, \\ MICHAL KOLAR ${ }^{6}$, HYNEK STRNAD ${ }^{6}$, JANA SACHOVA ${ }^{6}$, MILUSE HRADILOVA ${ }^{6}$, \\ MARTIN CHOVANEC ${ }^{7}$, HANS-JOACHIM GABIUS ${ }^{5}$, KAREL SMETANA JR. ${ }^{1,8}$ and ZDENEK FIK ${ }^{1,2}$ \\ ${ }^{1}$ Institute of Anatomy, 1st Faculty of Medicine, Charles University, Prague, Czech Republic; \\ ${ }^{2}$ Department of Otorhinolaryngology, Head and Neck Surgery, 1st Faculty of Medicine, \\ Charles University and University Hospital Motol, Prague, Czech Republic; \\ ${ }^{3}$ Department of Biomedical Research, \\ East-Slovak Institute of Cardiovascular Diseases, Inc., Kosice, Slovak Republic; \\ ${ }^{4}$ Department of Pharmacology, Faculty of Medicine, \\ Pavol Jozef Šafárik University in Košice, Kosice, Slovak Republic; \\ ${ }^{5}$ Institute of Physiological Chemistry, Faculty of Veterinary Medicine, \\ Ludwig-Maximilians University, Munich, Germany; \\ ${ }^{6}$ Laboratory of Genomics and Bioinformatics, Institute of Molecular Genetics, \\ Academy of Sciences of the Czech Republic, Prague, Czech Republic; \\ ${ }^{7}$ Department of Otorhinolaryngology and Head and Neck Surgery, 3rd Faculty of Medicine, \\ University Hospital Královské Vinohrady, Charles University Prague, Prague, Czech Republic; \\ ${ }^{8}$ BIOCEV, Charles University, 1st Faculty of Medicine, Charles University, Vestec, Czech Republic
}

\begin{abstract}
Background/Aim: Having previously initiated genome-wide expression profiling in head and neck squamous cell carcinoma (HNSCC) for regions of the tumor, the margin of surgical resecate (MSR) and normal mucosa (NM), we here proceed with respective analysis of cases after stratification according to the expression status of tenascin (Ten). Materials and Methods: Tissue specimens of each anatomical site were analyzed by immunofluorescent detection of Ten, fibronectin (Fn) and galectin-1 (Gal-1) as well as by microarrays.
\end{abstract}

This article is freely accessible online.

Correspondence to: Dr. Zdeněk Fík, Department of Otorhinolaryngology, Head and Neck Surgery, First Faculty of Medicine, Charles University and University Hospital Motol V Úvalu 84, 15006 Prague 5, Czech Republic. Tel: +420 224434301, Fax: +420 22443430, e-mail: zdenek.fik@lf1.cuni.cz; and Dr. Peter Gál, Department of Biomedical Research, East-Slovak Institute of Cardiovascular Diseases Inc., Ondavská 8, 04011 Košice, Slovak Republic. Tel: +421 552343251, Fax: +421 557891613, e-mail: pgal@vusch.sk orgalovci@yahoo.com

Key Words: Extracellular matrix, fibronectin, galectin, tenascin, tumor, stroma.
Results: Histopathological examination demonstrated that $\mathrm{Ten}^{+} \mathrm{Fn}^{+} \mathrm{Gal}_{-1}{ }^{+}$co-expression occurs more frequently in samples of HNSCC (55\%) than in NM (9\%; p<0.01). Contrary, the $\mathrm{Ten}^{-} \mathrm{Fn}^{+} \mathrm{Gal}_{-1} \mathrm{I}^{-}(45 \%)$ and $\mathrm{Ten}^{-} \mathrm{Fn}^{-} \mathrm{Gal}_{-1} \mathrm{I}^{-}$ $(39 \%)$ status occurred with significantly $(p<0.01)$ higher frequency than in HNSCC (3\% and $4 \%$, respectively). In MSRs, different immunophenotypes were distributed rather equally $\quad\left(\mathrm{Ten}^{+} \mathrm{Fn}^{+} \mathrm{Gal}_{-1} \mathrm{I}^{+}=24 \% ; \quad \mathrm{Ten}^{-} \mathrm{Fn}^{+} \mathrm{Gal}_{-} \mathrm{I}^{-}=36 \%\right.$; $\mathrm{Ten}^{-} \mathrm{Fn}^{-} \mathrm{Gal}-1^{-}=33 \%$ ), differing to the results in tumors $(p<0.05)$. Absence/presence of Ten was used for stratification of patients into cohorts without a difference in prognosis, to comparatively examine gene-activity signatures. Microarray analysis revealed i) expression of several tumor progressionassociated genes in Ten ${ }^{+}$HNSCC tumors and ii) a strong upregulation of gene expression assigned to lipid metabolism in MSRs of Ten ${ }^{-}$tumors, while NM profiles remained similar. Conclusion: The presented data reveal marked and specific changes in tumors and MSR specimens of HNSCC without a separation based on prognosis.

Faced with the enormous quantity of details on cell features, it is tempting to relate cases of differential expression to clinically-relevant properties. Conceptually, however, it could be possible that dysregulation occurs in such RNA 
profiles without any association to, most importantly, prognosis. Thus, it is an open question to what extent these profiles are similar or different in tissue specimens of tumors classified according to a certain immunophenotypical parameter. In our recent pilot study, we initiated a comparison of tumor, margin and normal tissue specimen in head and neck squamous cell carcinoma (HNSCC) (1). Building on the previously detected relationship of presence of a member of the family of adhesion/growth-regulatory galectins, a reader of the sugar code $(2,3)$, i.e. galectin-1 (Gal-1), with tumor invasiveness (4) and its activity to promote fibronectin (Fn) expression and fibroblast conversion to $\alpha$-smooth muscle actin ( $\alpha$-SMA) expressing myofibroblasts (5) as well as the significance of tenascin (Ten) expression (6), we here examine a panel of HNSCC cases always with specimen of the margin of surgical resecate (MSR) and normal mucosa (NM) according to presence of these three extracellular matrix (ECM) effectors.

Of fundamental importance, tumors of diverse metastatic potential and progression status differ in the composition of both tumor- and stroma-derived ECM components $(7,8)$. In this study, we first ask the question whether detection of the three proteins, expressed individually and/or in combination, provides prognostic information in the studied cohort of HNSCC patients. Following the immunohistochemical part that results in stratification according to the status of Ten expression, microarray analysis between $\mathrm{Ten}^{+} / \mathrm{Ten}^{-}$cases was performed in order to answer the question on occurrence of differences on the level of RNA presence. In addition to tumor tissues from specimens stratified according to Ten presence, we also ran array-based RNA profiling of MSR and $\mathrm{NM}$ of the two patient groups differing in Ten expression.

\section{Materials and Methods}

Tissue samples. The set of tissue specimen of i) HNSCC ( $\mathrm{n}=80$; for details on classification, see Table I; for details on anatomical localization of analyzed tumors, see Table II), of ii) normal oral mucosa $(\mathrm{NM})$ contralaterally to the primary tumor (NE - normal epithelium; $n=47$ ), and of iii) margin of surgical resecate (MSR, macroscopically healthy mucosa up to $1 \mathrm{~cm}$ to the tumor margin; $\mathrm{n}=45$ ) was obtained from the Charles University, 1st Faculty of Medicine, Department of Otorhinolaryngology, Head and Neck Surgery. All tissue samples were collected with informed consent of patients and approval of local ethical committee according to the Helsinki Declaration.

Tissue processing - immunohistochemistry. Tissue specimen of NE, HNSCC and MSR were cryoprotected by Tissue-Tek (Sakkura, Zoeterwoude, The Netherlands) and frozen in liquid nitrogen. Frozen sections, $7 \mu \mathrm{m}$ thick, were prepared by a Cryocut-E microtome (Reichert-Jung, Vienna, Austria).

Immunofluorescent detection of Ten, Fn and Gal-1. Frozen sections were carefully washed with phosphate-buffered saline (PBS, pH 7.2) and fixed by exposure to $2 \%(\mathrm{w} / \mathrm{v})$ buffered paraformaldehyde in
Table I. TNM classification

\begin{tabular}{ccccc}
\hline & G & T & N & S \\
\hline 0 & - & - & 24 & - \\
1 & 14 & 16 & 15 & 4 \\
2 & 39 & 36 & 38 & 8 \\
3 & 27 & 17 & 3 & 21 \\
4 & - & 11 & - & 47 \\
\hline
\end{tabular}

G: Grade; T: size of the primary tumor; $\mathrm{N}$ : degree of spread to regional lymph nodes; M: presence of distant metastasis; S: stage.

Table II. Anatomical sites of the primary tumors analyzed in the present study.

\begin{tabular}{lc}
\hline Primary site & Number of patients/microarray \\
\hline Oral cavity & $11 / 4$ \\
Oropharynx & $51 / 13$ \\
Hypopharynx & $5 / 1$ \\
Larynx & $13 / 8$ \\
\hline
\end{tabular}

PBS for five minutes. After extensive washing in PBS (three times for 10 minutes), the specimens were treated with PBS containing 0.2 $\%(\mathrm{v} / \mathrm{v})$ Triton X-100 (Sigma-Aldrich, St. Louis, MO, USA) and then washed in PBS. Antigen-independent binding of antibody via the $\mathrm{Fc}$ part was precluded by preincubation of specimens with porcine serum (DAKO, Glostrup, Denmark) diluted as recommended by the supplier. A murine monoclonal antibody against Ten-C and a rabbit polyclonal antibody against Fib (both from Sigma-Aldrich St. Louis, MO, USA) were applied as recommended by the supplier. Homemade rabbit polyclonal antibody against Gal-1 (9) that had thoroughly been tested for any cross-reactivity against other members of the galectin family, was used at a dilution of 1:50 (v/v). The specificity of immunodetection was ascertained by replacing the first-step antibodies by an irrelevant antibody of the same isotype (in the case of monoclonal antibody) or by omitting the first-step polyclonal antibody from pocessing. DNA was visualized by 4',6diamidino-2-phenylindole (DAPI) (Vector-Laboratories, Burlingame, CA, USA). All preparations were analyzed by a fluorescence microscope Eclipse 90i (Nikon, Tokyo, Japan) equipped with filter blocks for FITC, TRITC and DAPI and a Cool-1300Q CCD camera (Vosskühler, Osnabrück, Germany). Data were processed using the LUCIA 5.1 computer-assisted image analysis system (Laboratory Imaging, Prague, Czech Republic).

Microarray analysis. Material from a subset of 26 patients was processed using microarray techniques. Anatomical sites of specimens used for gene profiling are given in Table I. Briefly, total RNA was isolated using RNeasy Micro Kit reagents (QIAGEN, Germantown, MD, USA) from cryostat sections, following the procedure optimized for animal cells. The quantity and quality of RNA were determined using a NanoDrop ND-1000 spectrophotometer (NanoDrop Technologies LLC, Wilmington, DE, 


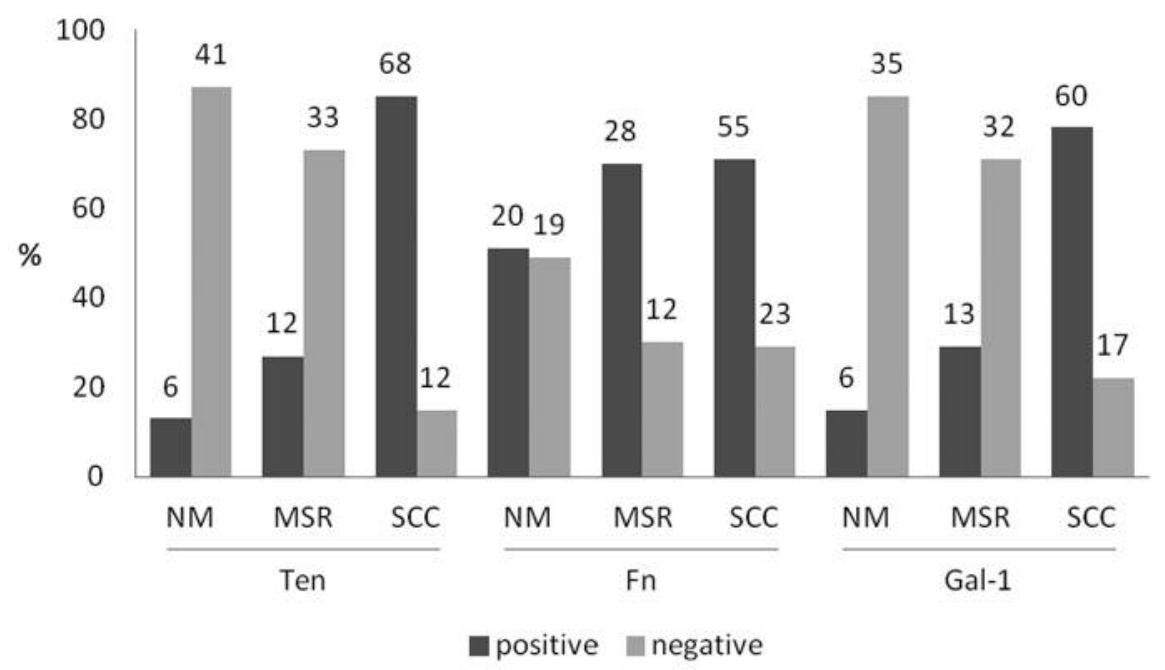

Figure 1. Distribution (\%) of specimen according to the category of immunohistochemical negativity/positivity for the studied ECM proteins, i.e. tenascin (Ten), fibronectin (Fn) and galectin-1 (Gal-1), in tissue sections of normal mucosa (NM), margin of surgical resecate (MSR) and squamous cell carcinoma (SCC). Number of evaluated patients is provided above each column.

USA) and an Agilent 2100 Bioanalyzer (Agilent Technologies, Santa Clara, CA, USA). Illumina HumanWG-6 V3 chips (Illumina, San Diego, CA, USA) were used for microarray analysis following a standard protocol: total RNA (150 ng) was amplified using an Illumina TotalPrep RNA Amplification Kit $\left(\right.$ Ambion $^{\mathrm{TM}}$; Thermo Fisher Scientific, Waltham, MA, USA), and 1,500 $\mathrm{ng}$ of the amplified RNA was hybridized to oligonucleotides presented on the chips according to the manufacturer's protocol. Including several technical replicates, 26 samples of tumor tissue (four Ten- tumors; $22 \mathrm{Ten}^{+}$tumors), 22 samples of stromal tissue (four samples of Tentumors and 18 samples of Ten ${ }^{+}$tumors), and 25 specimen of normal tissue (four samples of Ten- tumors and 21 of Ten $^{+}$tumors) were processed. To control the quality of the microarray analysis, we analyzed several samples in technical replicates.

The raw data were pre-processed using Genome Studio software (version 1.9.0.24624; Illumina) and further analyzed using the packages oligo (10) and limma (11) of the Bioconductor (12) within the R environment (R Foundation for Statistical Computing, Vienna, Austria; http://www.R-project.org/). In brief, transcription profiles were background corrected using a normal-exponential model, quantile normalized and variance stabilized using base 2 logarithmic transformation. A moderated $t$-test was used to detect differentially expressed transcripts after fitting the linear model $\mathrm{I} \sim$ Tissue * Presence of Ten in Tumor Stroma. Storey's q-value less than 0.25 (13) and a minimally 1.5 -fold change in expression intensity were required to consider genes as being differentially transcribed. The MIAME compliant data was deposited to the Array Express database (E-MTAB- E-MTAB-5852 and E-MTAB-6364).

Gene set enrichment analysis (GSEA) was performed using Fisher's exact test on KEGG pathways (14) and Gene Ontology (15). To consider the gene set significantly enriched by differentially expressed genes and to account for possible multiple testing issues, statistical significance of the test was set to $p<0.005$, enrichment odds ratio to at least two and at least three genes shared by the gene set and the set of differentially transcribed genes.

\section{Results}

Histology. Immunohistochemical detection of presence of the ECM proteins in sections of HNSCC, MSR and NM is exemplarily illustrated in Figures 1 and 2. There is an apparent similarity between the frequency of Ten and Gal-1 presence. These two proteins were consistently absent in NM and in MSR, but strongly expressed in HNSCC (NM or MSR vs. HNSCC; $p<0.01)$. Fn expression in NM showed almost equal distribution between positive and negative samples. In MSR and HNSCC, a shift to positive cases was seen (NM vs. MSR or HNSCC; $p<0.01)$.

Co-expression of markers to establish the $\mathrm{Ten}^{+} \mathrm{Fn}^{+} \mathrm{Gal}-1^{+}$ status occurred more frequently in samples of HNSCC $(\mathrm{n}=42 ; 55 \%)$ than in NM $(\mathrm{n}=3 ; 9 \% ; p<0.01)$. The most common combinations of marker parameters observed in NM were $\mathrm{Ten}^{-} \mathrm{Fn}^{+} \mathrm{Gal}_{-1}^{-}(\mathrm{n}=15 ; 45 \%)$ and $\mathrm{Ten}^{-} \mathrm{Fn}^{+} \mathrm{Gal}-1^{-}$ $(13 ; 39 \%)$. Of note, they were rather rare in HNSCC $(3 \%$ and $4 \%$, respectively; $p<0.01)$. Interestingly, all three combinations occurred with rather similar frequency in MSR, i.e. $\mathrm{Ten}^{+} \mathrm{Fn}^{+} \mathrm{Gal}_{-1}^{+}(\mathrm{n}=8 ; 24 \%), \mathrm{Ten}^{-} \mathrm{Fn}^{+} \mathrm{Gal}^{-1}{ }^{-}(\mathrm{n}=12$; $36 \%)$ and $\mathrm{Ten}^{-} \mathrm{Fn}^{-} \mathrm{Gal}^{-} 1^{-}(11 ; 33 \%)(p=0.568)$. Of note, the difference of frequency values between HNSCC and MSR samples was statistically significant $(p<0.05)$ (Figure 3$)$.

Considering association of positivity for Ten, FN or Gal-1 with clinical characteristics, no significant correlation between immunopositivity and nodal stage of tumors (Ten: $p=0.0715$; Fn: $p=0.906$; Gal-1: $p=0.963$ ) was found in the present study, Figure 4 illustrating data for Ten. The data on the other histopathological parameters, too, revealed no correlations to the status of expression of these three proteins. 

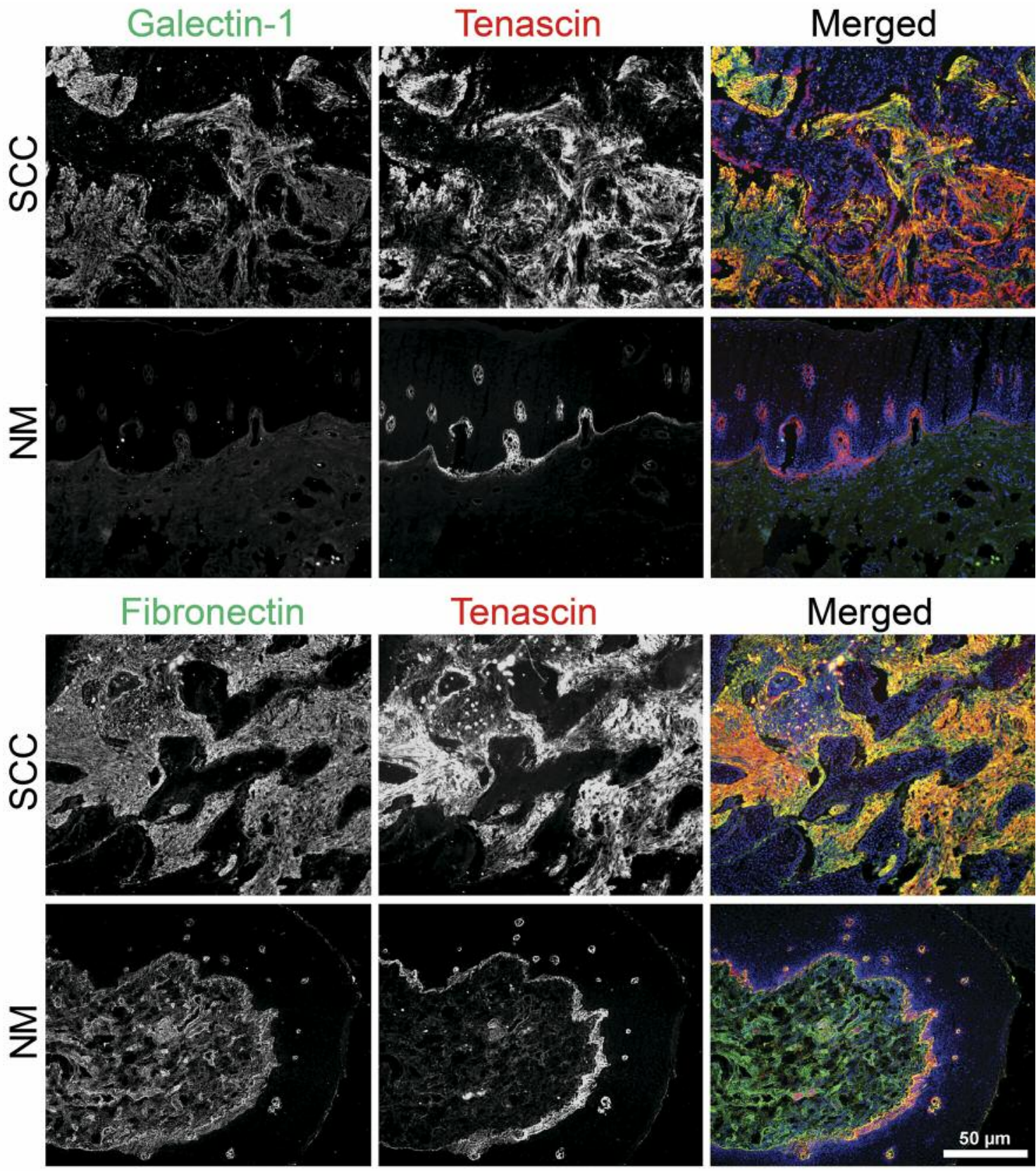

Figure 2. Immunofluorescent detection of pairs of galectin-1 (green signal) and tenascin (red signal) in the top part and of fibronectin (green signal) and tenascin (red signal) in the bottom part in frozen sections of normal mucosa (NM) and squamous cell carcinoma (SCC). Nuclei were counterstained with DAPI (scale bar $50 \mu \mathrm{m}$ ).

Prognostic correlations. Ten: No tendency for improved prognosis in short-term 2-year follow-up for patients with $\mathrm{Ten}^{+}$tumor stroma in both overall survival (OS) and diseasefree survival (DFS) was observed. The difference was not statistically significant (Figure 5; OS: $p=0.245$; DFS: $p=0.369)$. After 5-year follow-up, no difference was found between $\mathrm{Ten}^{+}$and $\mathrm{Ten}^{-}$samples (in both OS and DFS).
Positivity in MSR was likewise related to prognosis (2- and 5-year OS and DFS). The obtained data did not reach the level of statistical significance (2-year OS: $p=0.168$; 5-year OS: $p=0.218 ; 2$ y DFS: $p=0.0742 ; 5 y$ DFS: $p=0.122$ ). Respective data on 5-year OS and DFS were significantly higher in patients with $\mathrm{Ten}^{+} \mathrm{NE}(p<0.05)$ (Figure 5 and Figure 6). 


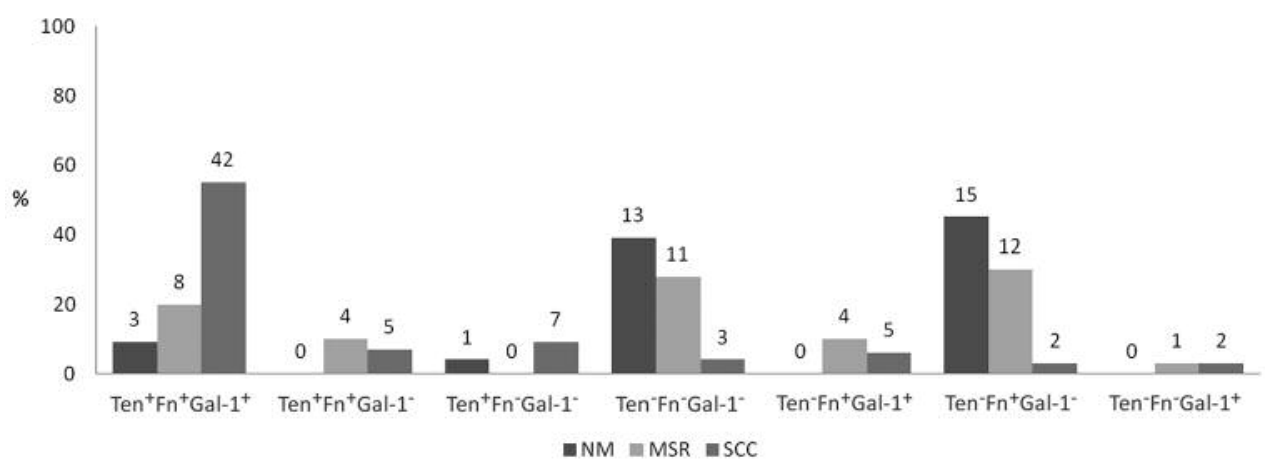

Figure 3. Distribution (\%) of specimen according to the categories of immunohistochemical negativity (-)/positivity (+) for tenascin (Ten), fibronectin (Fn) and galectin-1 (Gal-1) in tissue sections of normal mucosa (NM), margin of surgical resecate (MSR) and squamous cell carcinoma (SCC). Number of evaluated patients is provided above each column.

Fib: No correlation between Fn expression and patients' prognosis was delineated.

Gal-1: Although 2-year OS indicated that Gal-1+ tumors may have a relatively unfavorable prognosis, this correlation did not reach the threshold for statistical significance. Similarly, no association between Gal-1 expression and prognosis was found in peritumoral and normal tissues.

These immunohistochemical data thus document differences between HNSCC and NM but did not uncover a prognostically relevant association of Ten presence/absence. In the concept of our study design, we proceeded to map gene-expression profiles to answer the questions whether and which profile changes can occur.

Microarray analysis: a) RNA profiles differ between $\mathrm{Ten}^{-}$and $\mathrm{Ten}^{+}$tumors. When comparing RNA preparations from $\mathrm{Ten}^{+}$ and $\mathrm{Ten}^{-}$tumors, changes in 115 genes were detected. They are compiled in the Table III and Supplementary Table I (available at http://www.physiolchem.vetmed.uni-muenchen.de/summary/ anticancer_research/index.html) for the cases of most significant differences. The GSEA analysis of the Biological Process GO ontology terms (Table IV and Supplementary Table II available at http://www.physiolchem. vetmed.unimuenchen.de/summary/anticancer_research/index.html) revealed an association of differentially transcribed genes with the JAK-STAT signaling cascade (GO:0046427), with expression of several genes down-regulated in $\mathrm{Ten}^{+}$tumors (JAK2, LIF, and CYP1B1) and that of the NOTCH1 gene down-regulated in $\mathrm{Ten}^{-}$tumors. Also, a strong up-regulation of expression of genes involved in ncRNA processing (GO:0034470) in the Ten ${ }^{+}$tumors was seen. A gene belonging to this section is argonaute $2(\mathrm{AGO} 2)$, whose transcriptions appear to be significantly up-regulated in $\mathrm{Ten}^{+}$tumors compared to Ten ${ }^{-}$tumors, MSR, and NE, as also seen for the gene for pseudouridylate synthase 7 (PUS7), while gene expression for integrator complex subunit 1 (INTS1) is

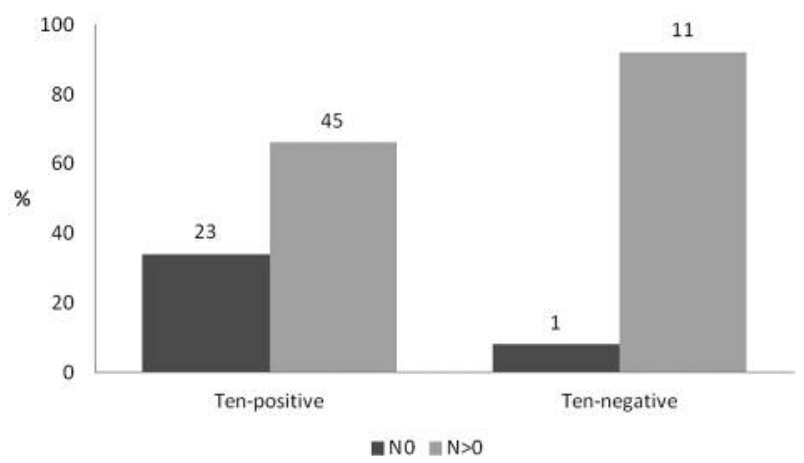

Figure 4. Distribution (\%) of specimen according to the categories of immunohistochemical Ten negativity/positivity based on lymph node staging (NO, absence of regional lymph node metastasis; $N>0$, presence of regional lymph node metastasis). Number of evaluated patients is provided above each column.

significantly down-regulated in $\mathrm{Ten}^{-}$tumors in comparison to $\mathrm{Ten}^{+}$tumors, MSR, and NE. GSEA of the Cellular Compartment GO ontology resulted in strong enrichment of the genes associated with components of the ECM and microenvironment (GO:0044421). Among them are lysyl oxidase-like 1 (LOXL1), whose expression is up-regulated in Ten ${ }^{-}$tumors, $\mathrm{Clq}$ and TNF related 1 (C1QTNF1), up-regulation seen in $\mathrm{Ten}^{-}$tumors and related MSR, and basal cell adhesion molecule (BCAM), upregulation detected in $\mathrm{Ten}^{-}$tumors-derived MSR and normal tissues. There were no Molecular Function GO ontology terms found among the genes differentially expressed between $\mathrm{Ten}^{+}$ and $\mathrm{Ten}^{-}$tumors (Figure 7).

Cases of gene dysregulation between $\mathrm{Ten}^{+} v s$. $\mathrm{Ten}^{-}$tumors furthermore include PRAME (preferentially expressed antigen in melanoma) strongly up-regulated in $\mathrm{Ten}^{+}$tumors, G6PC3 (glucose-6-phosphatase catalytic subunit 3) and IDUA, $\alpha$-L- 

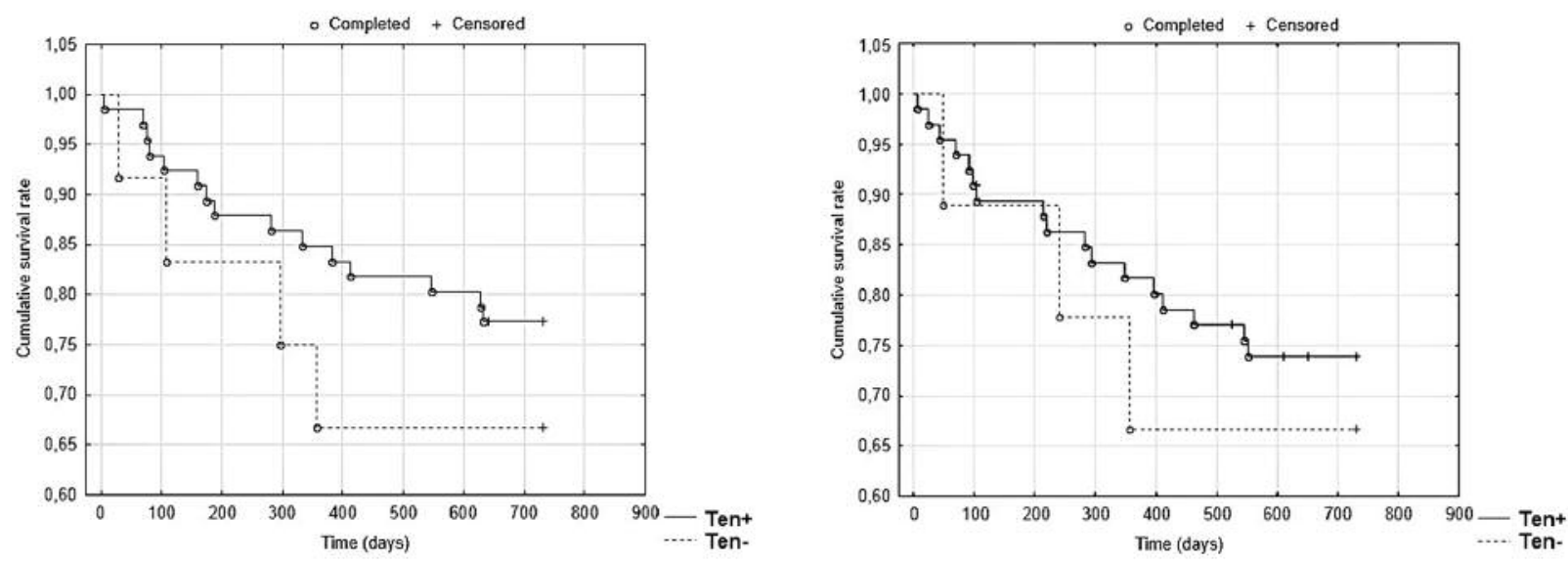

Figure 5. 2-year overall (left) and disease-free (right) survival in tenascin (Ten)-positive/negative tumors (completed - patients' data available during the whole evaluated interval or patient died during the evaluated interval; censored-patients'data are only partially available).

iduronidase, which are up-regulated in all $\mathrm{Ten}^{-}$samples, and also LIF, an interleukin 6 family cytokine, which is specifically up-regulated in $\mathrm{Ten}^{-}$tumors (for the most deregulated genes in this comparison, see Supplementary Table I).

Microaray analysis: b) RNA profiles of MSR differ between Ten ${ }^{-}$ and $\mathrm{Ten}^{+}$tumors. Comparing RNA preparations of MSR of patients with either $\mathrm{Ten}^{+}$or $\mathrm{Ten}^{-}$tumors, dysregulation of 154 genes was found (Table V and Supplementary Table I). GSEA analyses revealed that major changes occured in the metabolism of lipids (Table VI and Supplementary Table II). The most prominently enriched KEGG signaling pathway is the PPAR signaling pathway (hsa03320), with up-regulation of genes coding for peroxisome proliferator activated receptor gamma (PPARG), aquaporin 7 (AQP7), adiponectin ADIPOQ, perilipins 1 and 4 (PLIN1, PLIN4), lipoprotein lipase (LPL), and fatty acid desaturase 2 (FADS2) in MSR of patients with Ten ${ }^{-}$tumors. The glycerophosphatidyl metabolic pathway (hsa00561) also came up to be significantly enriched for up-regulated genes. Consistently, many GO terms associated with lipid metabolism are in the list of genes whose activity was enhanced in MSR of patients with $\mathrm{Ten}^{-}$tumors. These include cellular compartment lipid droplet (GO:0005811), lipid metabolic process (GO:0006629) and transferase activity (transferring acyl groups other than amino-acyl groups, GO:0016747). Other genes that showed significantly increased representation in the MSR of the patients with Ten ${ }^{-}$tumors are leptin (LEP) and galectin-12 (Gal12; LGALS12) (for the most deregulated genes in this comparison, see Figure 8 and Supplementary Table I).

Microarray analysis: c) RNA profiles of NM of the patients with $\mathrm{Ten}^{-}$and $\mathrm{Ten}^{+}$tumors are similar. The profiles of normal tissues of the cohorts of patients with $\mathrm{Ten}^{-} / \mathrm{Ten}^{+}$tumors were

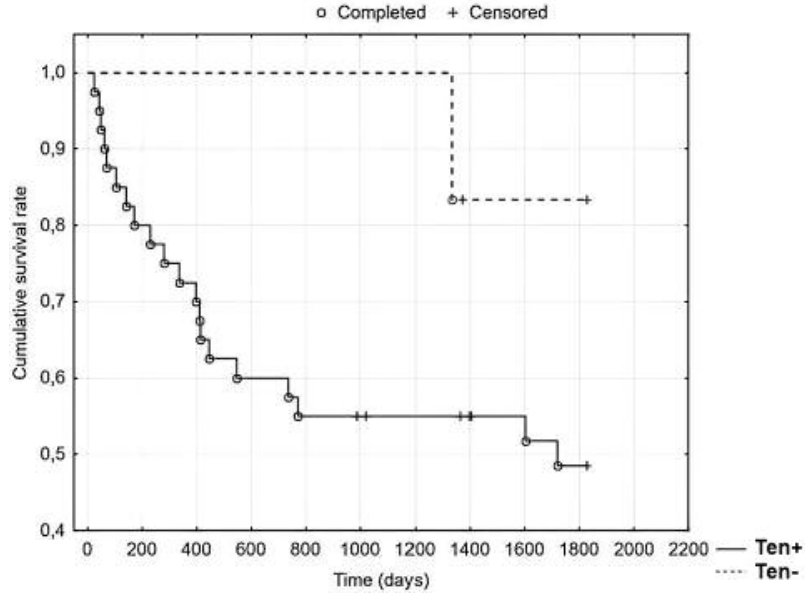

Figure 6. 5-year disease-free survival in tenascin-positive/negative normal mucosae (for explanation of completed/censored, see legend to Figure 5).

very similar. In cases appearing to differ in expression activity such as genes for RAB11B, a member RAS oncogene family, and pancreatic progenitor cell differentiation and proliferation factor (PPDPF), no statistical significance $(p=0.21)$ was reached. Obviously, MSR characteristics appeared to be more susceptible to an influence by the tumor than NM features, based on array-based RNA profiling.

\section{Discussion}

In the immunohistochemical part of our study, we revealed the possibility for a stratification according to the absence/presence of Ten. With relevance to prognosis, no 
Table III. Genes differentially transcribed after comparison of Ten ${ }^{+}$and Ten ${ }^{-}$tumors (IlogFCl>1, Storey's $q<0.1$ ).

\begin{tabular}{lccc}
\hline Entrez gene Id & Gene symbol & Definition & logFC \\
\hline Up-regulated in Ten+ tumors & & & q-Value \\
23532 & PRAME & Preferentially expressed antigen in melanoma & 1.74 \\
27161 & AGO2 & Argonaute 2, RISC catalytic component & 1.65 \\
54517 & PUS7 & Pseudouridylate synthase 7 (putative) & 1.15 \\
& & & 0.0386 \\
Down-regulated in Ten+ tumors & & & 0.062 \\
128434 & VSTM2L & V-set and transmembrane domain containing 2 like & -1.72 \\
3425 & IDUA & Iduronidase, alpha-L- & -1.36 \\
51733 & UPB1 & Beta-ureidopropionase 1 & 0.03 \\
147381 & CBLN2 & Cerebellin 2 precursor & 0.062 \\
10398 & MYL9 & Myosin light chain 9 & -1.34 \\
4059 & BCAM & Basal cell adhesion molecule (Lutheran blood group) & -1.31 \\
114897 & C1q and TNF related 1 & -1.0375 \\
92579 & C1QTNF1 & Glucose-6-phosphatase catalytic subunit 3 & -1.19 \\
51208 & G6PC3 & Claudin 18 & 0.03 \\
4016 & CLDN18 & Lysyl oxidase like 1 & -1.16 \\
22977 & LOXL1 & -1.14 & 0.0062 \\
1510 & AKR7A3 & CTSE & 0.0364 \\
3976 & LIF & Aldo-keto reductase family 7 member A3 & 0.0798 \\
441518 & RTL8B & LIF, interleukin 6 family cytokine & -1.12 \\
\hline
\end{tabular}

Table IV. GSEA analysis on GO Biological process ontology for the genes that are differentially expressed (DEG) between Ten ${ }^{+}$and Ten ${ }^{-}$tumors $(p<0.005$, odds ratio $>4$, and at least $3 D E G$ in the gene set $)$.

\begin{tabular}{|c|c|c|c|c|c|}
\hline Go Id & GO term & No. of genes with term & No. of DEG with term & Odds ratio & $p$-Value \\
\hline GO:0007214 & Gamma-aminobutyric acid signaling pathway & 23 & 3 & 25.5 & 0.000345 \\
\hline GO:0034470 & ncRNA processing & 392 & 9 & 4.17 & 0.000597 \\
\hline GO:0046427 & Positive regulation of JAK-STAT cascade & 73 & 4 & 9.92 & 0.000984 \\
\hline GO:1904894 & Positive regulation of STAT cascade & 73 & 4 & 9.92 & 0.000984 \\
\hline
\end{tabular}

correlation between Ten expression and grade, TNM stage and primary site of examined tumors, respectively, was discerned. Of particular note, no significant prognostic correlations was disclosed in all three groups of patients. A lack of association between Ten expression and histopathological features has previoulsy been reported in oral and pharyngeal cancers (16). Considering cell types other than tumor cells, Ten expression in cancer-associated fibroblasts was associated with patient age, tumor stage, lymph node metastasis, clinical stage, cancer recurrence and positively correlated with the presence of platelet-derived growth factor- $\alpha /-\beta$ and $\alpha$-SMA. Furthermore, its expression in cancer cells correlated with an increase in the population of tumor-associated macrophages, cancer recurrence and expression of hypoxia inducible factor-1 $\alpha$ (17).

The following comparison of gene expression profiles of $\mathrm{Ten}^{+}$and $\mathrm{Ten}^{-}$tumors by whole-genome transcriptome analysis led to detection of marked differences. The systematic comparison of profiles identified several genes that code for kinases and receptors relevant in tumor development that are transcriptionally dysregulated in Ten ${ }^{-}$tumor samples. Janus kinase 2 (JAK2), a case of down-regulation, is a non-receptor tyrosine kinase associated with cytokine receptors and involved in cell growth, development, differentiation or histone modifications and its overexpression predicts unfavorable prognosis for nasopharyngeal carcinoma (18). Notch1, the second prominent example of a down-regulated gene in $\mathrm{Ten}^{-}$tumors, controls cell-fate decisions including epithelial-to-mesenchymal transition and can hereby be involved a variety of developmental processes, mutations associated with several types of leukemia and HNSCC (19, 20). Leukemia inhibitory factor (LIF) can mediate proinvasive activation of stromal fibroblasts in cancer (21). Cytochrome $P 450$ CYP1B1 is involved in an NADPH- 


\section{Color Key and Histogram \\ Selected differentially expressed genes}
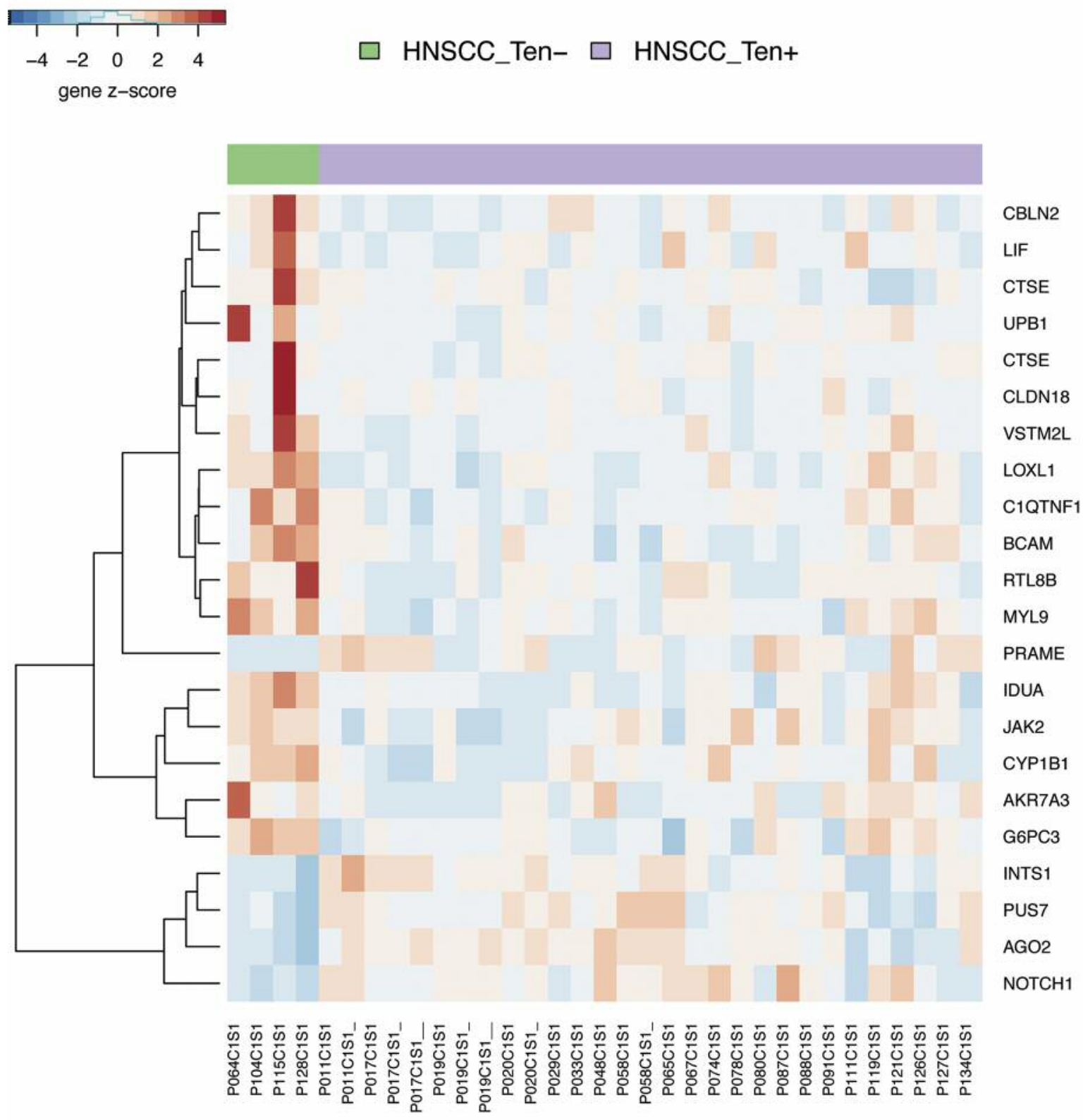

Figure 7. Transcriptome data on selected genes in preparations of tenascin-positive/negative (Ten ${ }^{+} /$Ten $\left.^{-}\right)$tissue ( $n=26$; for details, see Table II) of head and neck squamous cell carcinoma (HNSCC).

dependent electron transport pathway, oxidizing a variety of structurally unrelated compounds and promoting angiogenesis. Our data set on $\mathrm{Ten}^{+} / \mathrm{Ten}^{-}$tumors furthermore revealed strong enrichment of factors of the extracellular region. Among these, BCAM was found to be up-regulated in $\mathrm{Ten}^{-}$tumors, their stroma and matching normal tissues. Its expression is associated with immature states of human keratinocytes and it is induced in epithelial skin tumors and inflammatory epidermis $(22,23)$.

In this study, we next turned to the comparison of MSR specimens separated according to Ten expression of the tumor. Intriguingly, monitoring the MSR surrounding the 


\section{Color Key and Histogram \\ Selected genes involved in lipid metabolism and its regulation}
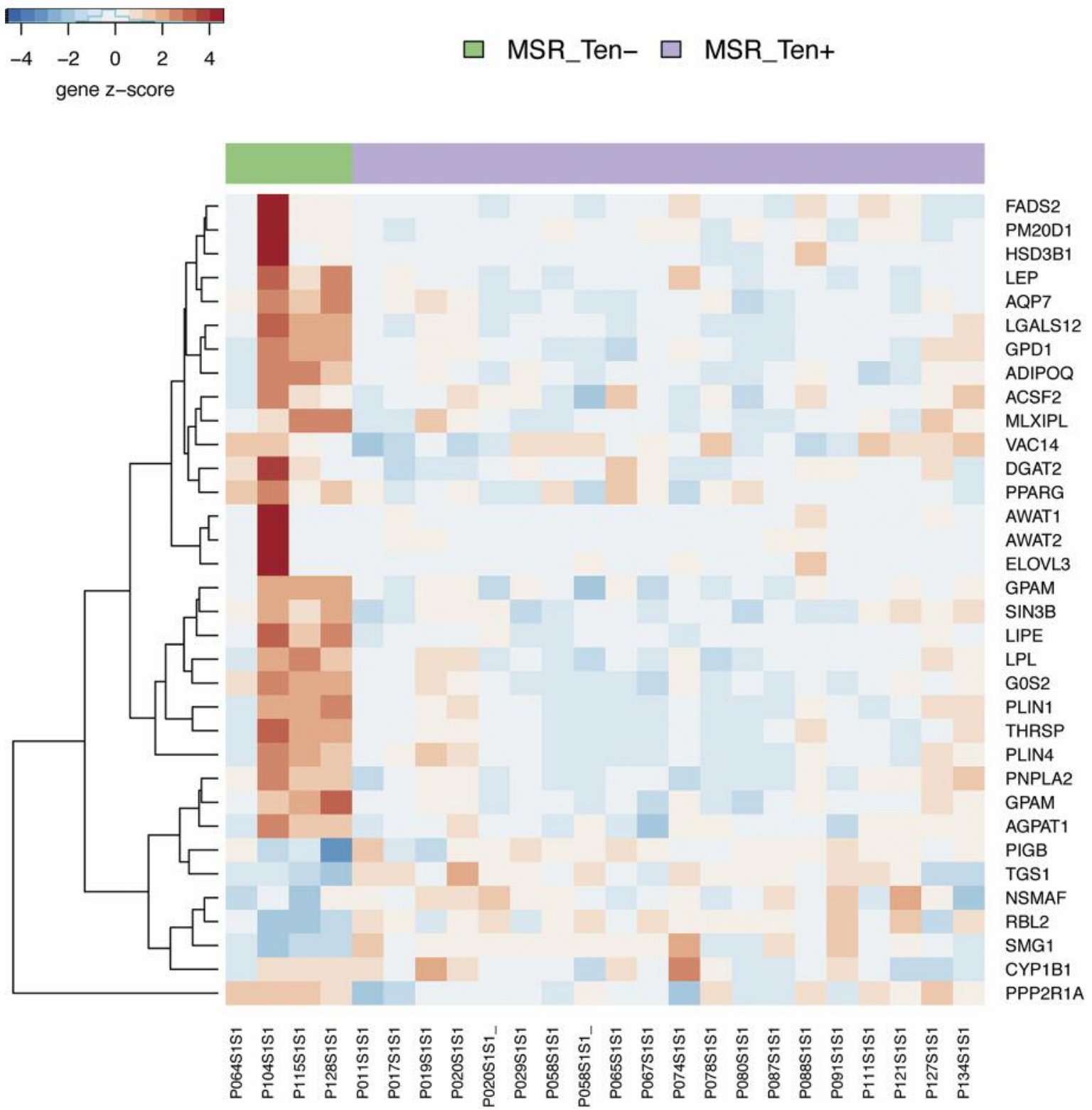

Figure 8. Transcriptome data on selected genes involved in lipid metabolism and its regulation in margin of surgical reseacate (MSR) preparations of tenascin-positive/negative $\left(\mathrm{Ten}^{+} / \mathrm{Ten}^{-}\right)$tumors.

$\mathrm{Ten}^{-}$tumors found a strong up-regulation of transcription of genes within the lipid metabolism. A prominent gene on this list is LEP. It is a key player in the regulation of energy balance and body weight (24). Moreover, LEP has also been described as a tumor-promoting gene for example in breast (25) and liver cancers (26). In addition, the multifunctional LEP is involved in the regulation of the ERK signaling (27) and can be apoptotic via the JAK2-STAT3 pathway and upregulation of BIRC5 expression, as well as regulates presence of matrix metalloproteinases (MMPs) and tissue inhibitors of MMPs $(28,29)$.

Multifunctionality, too, holds true for the adhesion/growthregulatory galectins $(2,30-32)$, Gal-12 expression exhibiting a similar increase as LEP does (see Supplementary Figure 1). 
Table V. Genes differentially transcribed in margin of surgical resecates (MSR) of Ten ${ }^{+}$and Ten ${ }^{-}$tumors (IlogFCl>1, Storey's q<0.1, best 20 by $\mid \log F C l)$.

\begin{tabular}{|c|c|c|c|c|}
\hline Entrez gene Id & Gene symbol & Definition & $\log \mathrm{FC}$ & q-Value \\
\hline \multicolumn{5}{|c|}{$\begin{array}{l}\text { Up-regulated in MSR of } \\
\text { patients with Ten+ tumors }\end{array}$} \\
\hline 6726 & $S R P 9$ & Signal recognition particle 9 & 1.23 & 0.003 \\
\hline \multicolumn{5}{|c|}{$\begin{array}{l}\text { Down-regulated in MSR of } \\
\text { patients with Ten }{ }^{+} \text {tumors }\end{array}$} \\
\hline 7069 & THRSP & Thyroid hormone responsive & -3.33 & $<0.001$ \\
\hline 729359 & PLIN4 & Perilipin 4 & -3.03 & 0.09 \\
\hline 50486 & GOS2 & G0/G1 switch 2 & -2.64 & 0.02 \\
\hline 5346 & PLIN1 & Perilipin 1 & -2.47 & 0.08 \\
\hline 4023 & $L P L$ & Lipoprotein lipase & -2.07 & 0.09 \\
\hline 6649 & SOD3 & Superoxide dismutase 3 & -2.04 & 0.008 \\
\hline 5997 & $R G S 2$ & Regulator of $\mathrm{G}$ protein signaling 2 & -1.92 & 0.09 \\
\hline 3991 & $L I P E$ & Lipase E, hormone sensitive type & -1.8 & $<0.001$ \\
\hline 56246 & MRAP & Melanocortin 2 receptor accessory protein & -1.8 & 0.008 \\
\hline 9370 & $A D I P O Q$ & Adiponectin, $\mathrm{C} 1 \mathrm{Q}$ and collagen domain containing & -1.78 & 0.009 \\
\hline 2819 & GPD1 & Glycerol-3-phosphate dehydrogenase 1 & -1.7 & 0.01 \\
\hline 83483 & PLVAP & Plasmalemma vesicle associated protein & -1.56 & 0.02 \\
\hline 84870 & $\mathrm{RSPO} 3$ & R-spondin 3 & -1.51 & 0.1 \\
\hline 3952 & $L E P$ & Leptin & -1.39 & 0.008 \\
\hline 85329 & $L G A L S 12$ & Galectin 12 & -1.38 & 0.005 \\
\hline 57678 & GPAM & Glycerol-3-phosphate acyltransferase, mitochondrial & -1.31 & 0.08 \\
\hline 57104 & PNPLA2 & Patatin like phospholipase domain containing 2 & -1.3 & 0.02 \\
\hline 375719 & $A Q P 7 P 1$ & Aquaporin 7 pseudogene 1 & -1.28 & 0.01 \\
\hline 364 & $A Q P 7$ & Aquaporin 7 & -1.27 & $<0.001$ \\
\hline
\end{tabular}

Table VI. GSEA analysis on GO Biological process ontology for the genes that are differentially expressed (DEG) between MSR of patients with $\mathrm{Ten}^{+}$and Ten- tumors $(p<0.005$, odds ratio $>10$, and at least 3 DEG in the gene set).

\begin{tabular}{|c|c|c|c|c|c|}
\hline Go Id & GO term & No. of genes with term & No. of DEG with term & Odds ratio & $p$-Value \\
\hline GO:0036155 & Acylglycerol acyl-chain remodeling & 7 & 3 & 104 & $<0.0001$ \\
\hline GO:0010889 & Regulation of sequestering of triglyceride & 11 & 3 & 52 & $<0.0001$ \\
\hline GO:0019915 & Lipid storage & 60 & 5 & 12.8 & $<0.0001$ \\
\hline GO:0019432 & Triglyceride biosynthetic process & 32 & 4 & 20 & $<0.0001$ \\
\hline GO:0055089 & Fatty acid homeostasis & 13 & 3 & 41.6 & 0.0001 \\
\hline GO:0046460 & Neutral lipid biosynthetic process & 34 & 4 & 18.6 & 0.0001 \\
\hline GO:0046463 & Acylglycerol biosynthetic process & 34 & 4 & 18.6 & 0.0001 \\
\hline GO:0030730 & Sequestering of triglyceride & 14 & 3 & 37.8 & 0.0001 \\
\hline GO:0050873 & Brown fat cell differentiation & 37 & 4 & 16.9 & 0.0002 \\
\hline GO:0010883 & Regulation of lipid storage & 40 & 4 & 15.5 & 0.0002 \\
\hline GO:0010888 & Negative regulation of lipid storage & 17 & 3 & 29.7 & 0.0002 \\
\hline GO:0031116 & Positive regulation of microtubule polymerization & 21 & 3 & 23.1 & 0.0005 \\
\hline GO:0031112 & Positive regulation of microtubule polymer./depolymer. & 24 & 3 & 19.8 & 0.0007 \\
\hline GO:0014823 & Response to activity & 59 & 4 & 10.2 & 0.0009 \\
\hline
\end{tabular}

This galectin's impact on growth control accounts for its current status as candidate tumor suppressor (33), in line with epigenetic gene silencing by promoter methylation and induction by butyrate in colorectal carcinoma lines $(34,35)$.
The herein reported up-regulation thus gives incentive to extend the immunohistochemical analysis of the galectin network in cancer, as described for example for colon cancer (36), and its surrounding tissue to this so far not studied 
family member, flanked by monitoring galectin binding using the labeled tissue lectin, an approach complementary to immunohistochemical monitoring (37-39). In this sense, determining this protein's presence, prompted by the array data presented herein, is likely to add to the evidence for galectin involvement in processes related to malignancy, as assumed following the detection of expression of tissue lectins in cancer more than 30 years ago (40).

In summary, our results reveal marked disparities of geneexpression signatures between i) tumor specimens stratified according to matrix glycoprotein without prognostic relevance and ii) MSR specimens in the formal category of lipid metabolism. These data point to plasticity of gene-expression profiles without necessarily bearing prognostic relevance and are relevant in principle for considerations of relating differences detected on this level to clinical parameters.

\section{Conflicts of Interest}

The Authors declare no potential conflicts of interest.

\section{Acknowledgements}

This work was supported by Progres Q28, GAUK 165015, and the Ministry of Health of the Czech Republic (Grant no. 15-28933A). The present study was also supported in part by the Agency for Science and Research under the contract no. APVV-0408-12, APVV-14-0731, APVV-16-0446, and APVV-16-0207). Support was also provided by Ministry of Education, Youth and Sports of CR within the National Sustainability Program II (project BIOCEVFAR; registration no. LQ1604) and project BIOCEV (grant no. CZ.1.05/1.1.00/02.0109). The present study usedthe equipment for metabolomics and cell analyses (grant no. CZ.1.05/2.1.00/19.0400) supported by the Research and Development for Innovations Operational Program, co-financed by the European regional development fund and the state budget of the Czech Republic. Inspiring discussions with Drs. B. Friday and A. Leddoz are gratefully acknowledged.

\section{References}

1 Zivicova V, Broz P, Fik Z, Mifkova A, Plzak J, Cada Z, Kaltner $\mathrm{H}$, Kucerova JF, Gabius H-J and Smetana K Jr.: Genome-wide expression profiling (with focus on the galectin network) in tumor, transition zone and normal tissue of head and neck cancer: marked differences between individual patients and the site of specimen origin. Anticancer Res 37: 2275-2288, 2017.

2 Kaltner H, Toegel S, Caballero GG, Manning JC, Ledeen RW and Gabius H-J: Galectins: their network and roles in immunity/tumor growth control. Histochem Cell Biol 147: 239256, 2017.

3 Gabius H-J: How to crack the sugar code. Folia Biol (Praha) 63: 121-131, 2017.

4 Valach J, Fík Z, Strnad H, Chovanec M, Plzák J, Cada Z, Szabo P, Sáchová J, Hroudová M, Urbanová M, Steffl M, Pačes J, Mazánek J, Vlček C, Betka J, Kaltner H, André S, Gabius H-J, Kodet R, Smetana K Jr, Gál P and Kolár M: Smooth muscle actin-expressing stromal fibroblasts in head and neck squamous cell carcinoma:increased expression of galectin- 1 and induction of poor prognosis factors. Int J Cancer 131: 2499-2508, 2012.

5 Dvořánková B, Szabo P, Lacina L, Gal P, Uhrova J, Zima T, Kaltner H, André S, Gabius H-J, Sykova E and Smetana K Jr: Human galectins induce conversion of dermal fibroblasts into myofibroblasts and production of extracellular matrix: potential application in tissue engineering and wound repair. Cells Tissues Organs 194: 469-480, 2011.

6 Guttery DS, Shaw JA, Lloyd K, Pringle JH and Walker RA: Expression of tenascin-C and its isoforms in the breast. Cancer Metastasis Rev 29: 595-606, 2010.

7 Nguyen-Ngoc KV, Cheung KJ, Brenot A, Shamir ER, Gray RS, Hines WC, Yaswen $\mathrm{P}$, Werb $\mathrm{Z}$ and Ewald AJ: ECM microenvironment regulates collective migration and local dissemination in normal and malignant mammary epithelium. Proc Natl Acad Sci USA 109: E2595-2604, 2012.

8 Pickup MW, Mouw JK and Weaver VM: The extracellular matrix modulates the hallmarks of cancer. EMBO Rep 15: 12431253,2014

9 Kaltner H, Seyrek K, Heck A, Sinowatz F and Gabius H-J: Galectin-1 and galectin-3 in fetal development of bovine respiratory and digestive tracts. Comparison of cell type-specific expression profiles and subcellular localization. Cell Tissue Res 307: 35-46, 2002.

10 Carvalho BS and Irizarry RA: A framework for oligonucleotide microarray preprocessing. Bioinformatics 26: 2363-2367, 2010.

11 Ritchie ME, Phipson B, Wu D, Hu Y, Law CW, Shi W and Smyth GK: Limma powers differential expression analyses for RNA-sequencing and microarray studies. Nucleic Acids Res 43: e47, 2015

12 Huber W, Carey VJ, Gentleman R, Anders S, Carlson M, Carvalho BS, Bravo HC, Davis S, Gatto L, Girke T, Gottardo R, Hahne F, Hansen KD, Irizarry RA, Lawrence M, Love MI, MacDonald J, Obenchain V, Oleś AK, Pagès H, Reyes A, Shannon P, Smyth GK, Tenenbaum D, Waldron L and Morgan M: Orchestrating high-throughput genomic analysis with bioconductor. Nature Methods 12: 115-121, 2015.

13 Storey JD and Tibshirani R: Statistical significance for genomewide studies. Proc Natl Acad Sci USA 100: 9440-9445, 2003.

14 Kanehisa M and Goto S: KEGG: Kyoto encyclopedia of genes and genomes. Nucleic Acids Res 28: 27-30, 2000.

15 Ashburner M, Ball CA, Blake JA, Botstein D, Butler H, Cherry JM, Davis AP, Dolinski K, Dwight SS, Eppig JT, Harris MA, Hill DP, Issel-Tarver L, Kasarskis A, Lewis S, Matese JC, Richardson JE, Ringwald M, Rubin GM and Sherlock G: Gene ontology: tool for the unification of biology. The Gene Ontology Consortium. Nature Genet 25: 25-29, 2000.

16 Atula T, Hedstrom J, Finne P, Leivo I, Markkanen-Leppanen M and Haglund $\mathrm{C}$ : Tenascin-C expression and its prognostic significance in oral and pharyngeal squamous cell carcinoma. Anticancer Res 23: 3051-3056, 2003.

17 Yang ZT, Yeo SY, Yin YX, Lin ZH, Lee HM, Xuan YH, Cui Y and Kim SH: Tenascin-C, a prognostic determinant of esophageal squamous cell carcinoma. PLoS One 11: e0145807, 2016.

18 He HL, Lee YE, Liang PI, Lee SW, Chen TJ, Chan TC, Hsing $\mathrm{CH}$, Chang IW, Shiue YL and Li CF: Overexpression of JAK2: a predictor of unfavorable prognosis for nasopharyngeal carcinoma. Future Oncol 12: 1887-1896, 2016. 
19 Leong KG, Niessen K, Kulic I, Raouf A, Eaves C, Pollet I and Karsan A: Jagged1-mediated Notch activation induces epithelialto-mesenchymal transition through Slug-induced repression of E-cadherin. J Exp Med 204: 2935-2948, 2007.

20 Cancer Genome Atlas Network: Comprehensive genomic characterization of head and neck squamous cell carcinomas. Nature 517: 576-582, 2015.

21 Albrengues J, Bourget I, Pons C, Butet V, Hofman P, TartareDeckert S, Feral CC, Meneguzzi G and Gaggioli C: LIF mediates proinvasive activation of stromal fibroblasts in cancer. Cell Rep 7: 1664-1678, 2014.

22 Schon M, Klein CE, Hogenkamp V, Kaufmann R, Wienrich BG and Schon MP: Basal-cell adhesion molecule (B-CAM) is induced in epithelial skin tumors and inflammatory epidermis, and is expressed at cell-cell and cell-substrate contact sites. J Invest Dermatol 115: 1047-1053, 2000.

23 Schon M and Schon MP: Expression of basal-cell adhesion molecule (B-CAM) is associated with immature states of human keratinocytes. J Invest Dermatol 117: 995-997, 2001.

24 Mechanick JI, Zhao S and Garvey WT: Leptin, an adipokine with central importance in the global obesity problem. Glob Heart, 2017. doi: 10.1016/j.gheart.2017.10.003. [Epub ahead of print].

25 Barone I, Catalano S, Gelsomino L, Marsico S, Giordano C, Panza S, Bonofiglio D, Bossi G, Covington KR, Fuqua SA and Andò S: Leptin mediates tumor-stromal interactions that promote the invasive growth of breast cancer cells. Cancer Res 72: 1416-1427, 2012.

26 Xiong Y, Zhang J, Liu M, An M, Lei L and Guo W: Human leptin protein activates the growth of HepG2 cells by inhibiting PERK-mediated ER stress and apoptosis. Mol Med Rep 10: 1649-1655, 2014.

27 Jiang L, Li Z and Rui L: Leptin stimulates both JAK2-dependent and JAK2-independent signaling pathways. J Biol Chem 283: 28066-28073, 2008.

28 Park HY, Kwon HM, Lim HJ, Hong BK, Lee JY, Park BE, Jang Y, Cho SY and Kim HS: Potential role of leptin in angiogenesis: leptin induces endothelial cell proliferation and expression of matrix metalloproteinases in vivo and in vitro. Exp Mol Med 33: 95-102, 2001

29 Jiang H Yu J, Guo H, Song H and Chen S: Up-regulation of survivin by leptin/STAT3 signaling in MCF-7 cells. Biochem Biophys Res Commun 368: 1-5, 2008.

30 Kaltner H and Gabius H-J: A toolbox of lectins for translating the sugar code: the galectin network in phylogenesis and tumors. Histol Histopathol 27: 397-416, 2012.

31 Smetana K Jr., André S, Kaltner H, Kopitz J and Gabius H-J: Context-dependent multifunctionality of galectin-1: a challenge for defining the lectin as therapeutic target. Expert Opin Ther Targets 17: 79-392, 2013.
32 Solís D, Bovin NV, Davis AP, Jiménez-Barbero J, Romero A, Roy R, Smetana K Jr. and Gabius H-J: A guide into glycosciences: How chemistry, biochemistry and biology cooperate to crack the sugar code. Biochim Biophys Acta 1850: 186-235, 2015

33 Yang RY, Hsu DK, Yu L, Ni J and Liu FT: Cell cycle regulation by galectin-12, a new member of the galectin superfamily. J Biol Chem 276: 20252-20260, 2001.

34 Katzenmaier EM, André S, Kopitz J and Gabius H-J: Impact of sodium butyrate on the network of adhesion/growth-regulatory galectins in human colon cancer in vitro. Anticancer Res 34: 5429-5438, 2014.

35 Katzenmaier EM, Kloor M, Gabius H-J, Gebert J and Kopitz J: Analyzing epigenetic control of galectin expression indicates silencing of galectin- 12 by promoter methylation in colorectal cancer. IUBMB Life 69: 962-970, 2017.

36 Dawson H, André S, Karamitopoulou E, Zlobec I and Gabius H$\mathrm{J}$ : The growing galectin network in colon cancer and clinical relevance of cytoplasmic galectin-3 reactivity. Anticancer Res 33: 3053-3059, 2013.

37 Plzák J, Betka J, Smetana K Jr., Chovanec M, Kaltner H, André S, Kodet R and Gabius H-J: Galectin-3 - an emerging prognostic indicator in advanced head and neck carcinoma. Eur J Cancer 40: 2324-2330, 2004.

38 Manning JC, García Caballero G, Knospe C, Kaltner H and Gabius H-J: Network analysis of adhesion/growth-regulatory galectins and their binding sites in adult chicken retina and choroid. J Anat 231: 23-37, 2017.

39 Roy R, Cao Y, Kaltner H, Kottari N, Shiao TC, Belkhadem K, André S, Manning JC, Murphy PV and Gabius H-J: Teaming up synthetic chemistry and histochemistry for activity screening in galectin-directed inhibitor design. Histochem Cell Biol 147: 285301, 2017.

40 Gabius H-J, Engelhardt R and Cramer F: Endogenous tumor lectins: overview and perspectives. Anticancer Res 6: 573-578, 1986. 